\title{
Machine Learning Systems in Epidemics: In the Al of the Storm
}

\author{
Khalid Khader \\ MBBS, D-Ortho \\ MSc Quality and Safety in Healthcare Management (QSHM) (RCSI) \\ ORCID: https://orcid.org/0000-0003-1092-1498
}

\begin{abstract}
COVID 19 or the novel corona virus has hit the human race in a way which has never been documented before. Flu epidemics and pandemics have happened in the past, but few have had devastating global impact as the COVID pandemic. The pandemic has shown us how unprepared we are to something novel, something as tiny as a RNA strand which has caused havoc in the life and resources of most countries. The economic and social implication of the pandemic has been immense but the most concerning aspect of the epidemic is the vulnerability of the treating community to the disease, which raises very important questions on introspection. Flattening the curve is the strategy to prevent the overwhelming of the healthcare system during any epidemic and not a way to curb the infection itself(1). As the pandemic has progressed, the mortality and morbidity of healthcare workers has been increasingly documented and the implication of this on an already compromised system with infected, isolated or quarantined care providers(2) raises questions on the preparedness of systems for future epidemics. An elusive vaccine is not the answer to the problem of epidemics as most epidemics are novel and the next epidemic seems not far away, as history serves as the best early warning system. Epidemics will happen, but our response to the same needs to be better than the present standards of care which leaves critical care workers at risk. Many innovative ideas ranging from indigenous PPEs to telemedicine have been used as ways around the system, which can only be considered as desperate measures during desperate times. Understanding epidemics with the help of innovative technology opens up doors to novel ways to tackle novel problems. The use of Artificial Intelligence as the first response to epidemics addresses the problem of protecting the most critical and finite resource of Health Care Workers $\mathrm{HCW}$ and utilizing them ergonomically in domains where they are irreplaceable(3). Using the Natural Language Processing NLP as the first line of defense against epidemics(4) needs a paradigm shift in the current thinking process as the potential for this simple yet immense resource available at the fingertips of the common man needs to be tapped with caution. The use of NLP in Machine Learning ML, their use in other diseases and the possibility of using it as the first response to an epidemic thereby optimizing care and protecting critical resources will be discussed in this article.
\end{abstract}

\section{General Terms}

Pattern recognition, natural language processing, deep learning algorithms

\section{Keywords}

Artificial intelligence, Machine Learning systems, Epidemics, First Responders, Healthcare workers, comorbidities, COVID pandemic, Connected devices, NLP, Personalized medicine, $\mathrm{AI}$ in healthcare, $\mathrm{AI}$ in healthcare quality.

\section{INTRODUCTION}

Any epidemic can be understood easily by the four stages as documented in the evidence base(5). The first case is the export of the case from an affected region by a traveller/ travellers (index case/case zero) who get infected by the pathogen. The second stage or first cluster is the stage of local transmission where the traveller transmits the pathogen to close contacts, the stage when spread can be stopped by extensive contact tracing, isolation and treatment of cases. The third stage is the community spread where the local transmission when left unchecked, results in the spread to the community through both symptomatic and asymptomatic contacts. When the community spread is left unchecked the fourth stage of explosion of the epidemic results, which can become a pandemic if enough places are affected globally. Understanding this premise is necessary to understand the response of the healthcare system to the epidemic at different stages of the epidemic. The lockdowns, stoppage of international travel, isolations, quarantines and social distancing(6) have literally left the global community in a standstill, which is one of the techniques to prevent the spread of the disease. The efficacy of these measures depend on many factors including the epidemiological stage of the disease, the strictness of the lockdown, the compliance of the community to the lockdown and the economic, social, political and geographic demographics of a country(7).

The focus of the discussion is about the judicial use of resources during an epidemic(8), which could have a big say on the shaping up of the epidemic itself. The HCWs happen to be one of the most precious, yet vulnerable group of individuals who have to be protected in order to screen, isolate and treat positive cases during an epidemic. They happen to be the first line of contact in any disease and hence the increased risk of getting infected, spreading it to others, or even worse being isolated or hospitalized themselves when their services are of utmost importance(9). All HCWs have the occupational hazard of getting sick when treating diseases which becomes a huge obstacle in contagious diseases like epidemics unlike chronic conditions which are nontransmissible. The fact that HCWs are vulnerable to infections at all stages of the epidemic makes this all the more an important issue to be understood as many hospitals have become confinement zones with cases spreading to patients without proper screening, as witnessed during the recent COVID pandemic. The HCWs have to be isolated, quarantined and treated for complications once contact without proper PPE has happened for obvious reasons. 


\section{PRESENT MODEL OF RESPONSE TO EPIDEMICS AND CHALLENGES:}

The present system of response for a suspected case in an epidemic is quite different from the conventional emergency/ outpatient department cases where the patient directly interacts with HCWs. Any good system would have dedicated hotline numbers which have to be contacted once a suspected case in accordance to the symptoms the person presents with(10). Once the telephonic conversation is done the respondent decides on the diagnosis, severity and further course of action which needs to be made in accordance to the individual case. The systems are so good that once there is strong evidence on to contact history or symptoms these patients are transported in dedicated ambulances to dedicated hospitals which are equipped with facilities for screening, isolation and treatment with PPEs and all the necessary precautions. Though many countries did not have such a response to the COVID pandemic, this at first glance would be an ideal response, but deep analysis of the system reveals a lot of flaws. In a pandemic this system will fail as the number of cases will be very high, especially if there is community spread and the resources could get stretched to levels whereby the plan will not be effective at all. The other problem would be the non-availability of enough test kits especially in the beginning of the epidemic to screen all the sick patients(11). There is enough evidence to show the unavailability of PPEs in even the ICU setups once the cases had exploded and hence the importance of flattening the curve so as to prepare the healthcare system to face the next wave of patients. The telephonic interview through hotlines is handled by HCWs whose expertise could be utilized in domains where they are actually necessary. The telephonic interview is quite subjective as the sensitivity and specificity of the screening questionnaire further determines the use of precious resources such as transport and testing. The accessibility and the ease of use of these hotlines are again a matter of debate as the elderly and more sick individuals find it difficult to go through this process due to logistic concerns. Further a person may symptomatically worsen after one particular interaction which may not be identified by a different receiver on a later conversation.

Epidemics have the peculiarity of spreading rapidly and hence the need for isolation and quarantines as part of the treatment for both positive and contact cases. Mild cases without symptoms which do not need hospital admission in COVID 19 are home quarantined for up to three weeks in accordance to the incubation period of the disease(12). The patient in home quarantine maybe stepped up for admission if their symptoms worsen and hence the need for constant surveillance. The progression of mild symptoms to frank breathlessness have been very concerning issues in the COVID pandemic and the actual mortality due to such exacerbations(13), especially in elderly will come to account only after the epidemic has been contained. The need for constant surveillance of such cases shows one of the many gaps we have to address in future cases of epidemics for making a reliable system which actually works in spite of the uncertainties. Some really good systems have been following up patients through telephonic interviews but such interactions have been possible and relevant only in places where the disease has been relatively well under control or where the incidence has been less(14). Thus triaging, screening and constantly checking on patients would add on to an already stressed healthcare system which could get lost in translation if the epidemic becomes explosive as witnessed in Europe. The identification of high risk individuals is yet another challenge in which the current system has failed due to the timeline of response. The COVID pandemic has raised relevant questions on the early identification of high risk individuals on the basis of age, pregnancy, comorbidities like diabetes, hypertension, obesity, cardiovascular disease and chronic kidney diseases(15). The understanding of these demographics and comorbidities will help in managing and prioritizing care especially when there is community spread as these subset of patients happen to be the most vulnerable in terms of severity, complications and eventually increased case fatality(16). Many classifications of the current pandemic consider mildly symptomatic individuals with comorbidities as moderately severe disease(17). Hence early identification of these high risk groups with a degree of certainty would make a huge difference in the shaping up of the epidemic in a particular region.

\section{FUTURE COURSE OF EPIDEMICS}

The current pandemic is a lot trickier than the ones before due to a strange phenomenon of reinfection/ reactivation of the virus after becoming symptomatically and serologically negative as documented in Rhesus monkeys(18). We are still in the early days of understanding this phenomenon in humans (19) as there are unofficial reports of more than 14 percent of serologically negative cases becoming symptomatic and seropositive after a period of 3-4 weeks. This has a big impact on the herd immunity(20), the main factor which could help in controlling the disease once people get immune to the disease either through recovery from the infection or through the use of vaccine. Hence the follow up of recovered patients is of high importance when dealing with a contagious disease of such high infectivity and mortality. Very few places have successfully implemented this kind of follow ups as most of the healthcare systems have been overwhelmed with cases and the importance of following up these cases have not been pursued with enough conviction. Hospitals and HCWs are considered as critical resources but are at risk during the beginning of an epidemic as they are in contact with patients till strict guidelines and screening becomes the norm, as seen in the present COVID epidemic(21). An asymptomatic patient with other diseases who reaches the hospitals or a healthcare worker who had come in contact with a patient who is yet to be diagnosed is a ticking time bomb in case of epidemics. It is ethically impossible for healthcare organizations to reject treatment for such diseases which need care, stating reasons of proactive prevention of contagion spread. This makes the resources in the healthcare organization as vulnerable as the general population and this conundrum needs to be addressed if a secure and foolproof system for the future needs to become a reality(9). The problem with the epidemic in the modern era is the easy availability of information which makes every other person come to conclusion that they are indeed infected and hence need medical attention. This has been recorded in places where testing was mandated only to cases which were symptomatic and the huge number of negative cases in places where community testing is not done is testimony to this assumption. So not only are test kits, another critical resource, used on patient not needing attention but when the cases explode in due time the same resource becomes hard to find for deserving patients(11). Further the dispelling of doubts of people through a proper interaction would decrease the number of people seeking medical attention to far less than what has actually been addressed. Much of this waste in resources could be effectively managed once a personalized yet easily available parallel system of 
screening is deployed which can be far more effective in screening and diagnosing the disease and yet conserves valuable human resources.

The numbers about epidemics in the present century are not encouraging as more than sixty epidemics have emerged in the last two decades and the incidence seems to be increasing disproportionately when compared to the earlier two centuries(22). A specific approach towards an epidemic has not been a successful one as every year the healthcare system is faced with a challenge of a new strain of virus or an exotic pathogen which makes vaccines and herd immunity a distant dream as much of the damages are already done by the time these measures can be implemented. There has been much focus on the R0 or R-naught (23)which is the average number of secondary cases, one infected case would produce in a completely susceptible population and this in turn determines herd immunity which is the minimum number of cases which needs to be infected or recovered from the infection to provide a blanket immunity for the population which is not yet infected. The herd immunity threshold depends on a single parameter known as R0, or the basic reproduction number. If we consider a hypothetical pathogen with an $\mathrm{R} 0$ of 4 , this means that, on average, one infected host will infect 4 others during the infectious period assuming no immunity exists in the population(26). The early understanding of an R0 of COVID was 2.5 which roughly estimates to a fifty percent infectivity as necessary to have herd immunity has been challenged as new data have emerged(25). More recent estimates place the R0 as high as 5.7 in some place, although many estimates fall within the range of 2.5 to 3.5 (26). This variation reflects the difficulty of obtaining accurate R0 estimates in an ongoing pandemic, and the current estimated SARS-CoV-2 R0 values likely do not indicate a complete picture of the transmission dynamics across all countries. The next epidemic may not be as global or severe as the present one but wanting the system to respond in a much better way than it has done this time around should be considered with immense proactivity. Using the global interconnectivity and technology for the advancement of response systems needs to be the premise on which improvements have to be implemented. The understanding of the current model of response, at least with regard to screening, identification of high risk cases and follow up of isolated/ recovered patients can be effectively done once the decision making process has been defined. These are common variables in any epidemic, and the specificity with respect to a particular epidemic will change in accordance to the epidemiological variables involved for that specific disease. Most of these processes can be replaced by Machine Learning ML systems which can be customized in a much better way than the present system in place. The subjectivity of the decision making process can be replaced by an objective ML system which can be much more effective than the current human interaction systems.

\section{HOW MACHINE LEARNING SYSTEMS CAN WORK DURING EPIDEMICS:}

Given the current understanding of epidemics, a ML program or device would be a much more accessible yet safe option to the present response to epidemics(27). The use of ML as a support for processes to support clinicians and healthcare workers is beyond the scope of this discussion but only throws light into how much can be achieved once the power of ML is harnessed optimally. The problem of protecting the HCWs and testing kits can be easily solved once an AI program is trained to ask relevant questions to the user and document their responses(28) and reach a conclusion in accordance to the dataset on which it has been trained with. Since the ML interacts with the users away from the hospitals, the objective of HCWs safety is easily achieved and training of the AI systems to decide on whether a patient requires immediate medical attention(29), be it as part of the epidemic or otherwise can be defined with a certain degree of certainty by using the concept of forward triaging(30). Further, the ML has the edge of immense personalized data beforehand of the first clinical encounter that it can easily diagnose high risk conditions with comorbidities and allocate resources and system warnings in accordance to the logistics involved in healthcare systems(30). The fact that an AI system can be trained not only to correctly identify the high risk group but can be used to alert clinicians with the help of data from connected devices through proper patient engagement provides it with a competitive advantage. Once definite processes are identified the ML system can be trained to answer common questions and give the user reliable information to these queries thus empowering patients in a way which is yet to be realized by the present system. A relevant algorithm which interacts with individuals in understanding and answering their actual concerns which can thereby save valuable resources both in the form of HCW interactions and hospital visits itself is the need of the hour(31). The optimal use of connected health devices could be used as a safe strategy to identify comorbidities and their control with the current management regimes which can be of immense benefit in tracing and tracking high risk vulnerable patient subsets(32). The current pandemic, in spite of all the harm it has caused has asked very relevant questions on to the approach to future epidemics and how the current state of relative helplessness can be overcome. Connected health devices could be the answer to treatment and management of comorbidities which play a decisive role in the progress of the epidemic, beyond the epidemic itself. The current COVID pandemic has enough data to suggest that patients with comorbidities have more severe infections and complications and more than ninety percent of the case fatality or mortality has been seen in patients with comorbidities(17). Unlike the current system in place for treatment of comorbidities which has a three month period between lab testing and appointments with clinicians and any difficulty in between this window is dealt with as an emergency visit, the connected devices provide a more dynamic and comprehensive understanding of these disease states by regular patient engagement thereby presenting better results in real time.

\section{CAN AI ACT AS A FIRST RESPONDER IN EPIDEMICS?}

Once the resources have been secured and the comorbidities have been identified we can now take a look into using ML systems as first line of defense against epidemics. Screening of an epidemic using an AI system seems to be the most logical way of going about, provided we can develop such systems. The encroachment of smart devices into the private lives of individuals can be used as an advantage as ML chat bots or AI apps can be used to screen users with a proper programs which can identify the symptoms by interacting with the user(33). The use of NLP or Natural Language Processing for screening, high risk identification and follow up(4) opens up possibilities of being battle ready if, and when the next epidemic strikes. NLP has been used extensively in various AI systems including internet search engines, social media, smart devices and smart apps in mobile devices. ML through NLP has the potential to identify patients with comorbidities but more importantly the AI system can be 
trained to identify symptoms by recording and analyzing changes in voice pattern, breathing pattern and intervals, cough intensity and pattern, and levels of dyspnea which can be used as a potent tool to screen patients(34). The advantage of these AI programs is that they have a baseline recording as to when the user was normal and can pick up the subtle changes which happen in the voice, cough and breathing patterns especially in respiratory conditions(35) which can be an invaluable source of information. The additional advantage of understanding variations of symptoms as in home quarantined patients or people who have recovered with doubts on reinfection/ reactivation through additional recordings can be done by a competent AI system. There have been efforts already to collect data in various AI initiatives during the current pandemic whereby voice samples of healthy and COVID infected patients have been collected for recording and analysis of various parameters which can be used for machine learning datasets(34). The voice samples include parameters like breathing sounds (fast and slow), phonation of sustained vowels, counting numbers at slow and fast rates and the rate and quality of respiration which are documented during the recording. The data set can be further enriched by collecting metadata on the participant's age, gender, geographic location, current health status both symptomatically and through lab diagnosis (in diagnosed and recovered patients), and presence of comorbidities(37) and special conditions like pregnant women and children. Such programs would aim at collecting data on the so called 'infection prints' from the voice samples which will be recorded and used by ML, both for learning and testing before the AI algorithm can be used in real life scenarios. When the ML systems are fine-tuned with enough data the whole AI system can be used as a web based/ smart app to detect and screen cases after proper validation of the accuracy and approval from competent authorities(37). The fact that these are all ideas in an infant state which need consensus among experts and competent authorities to become applicable reality needs to be understood by all involved and hence the time sensitivity of the discussion as we are still in the middle of the epidemic.

\section{HOW FEASIBLE IS ML AS A FIRST RESPONDER AND ITS LIMITATIONS:}

AI systems in the present age have the scope of becoming a game changer, especially in cases of infectious and contagious diseases given their ability to understand patterns and associations(37) when provided with good enough data sets. The evidence bases about the current pandemic are only being published and hence the process will need constant revisiting and retesting of the current hypothesis in hand. The bright side of this exercise is that once general rules, consensus and dictums have been finalized for epidemics/ pandemics through competent authorities the process of building a ML algorithm as the first line of defense against pandemics is only a matter of time. While clinicians and HCWs are waging their battles against this dreaded pathogen the infrastructure and planning to win the war against future epidemics should be laid as soon as possible. There is no bad feeling for a physician than to realize that they are losing their patients despite their best efforts and in these cases risking their own life doesn't seem to make much of a difference. The greatest advantage of an AI system is its accessibility to everyone(39), unlike hospitals whose services come at a premium price, be it to the governments, insurance companies or patients. The very fact that AI systems can go on to eliminate the necessity of hospitals(28), which have traditionally worked as an interface between physicians, healthcare workers and patients for obtaining appropriate care opens up a variety of opportunities. Realization of the fact that this interface is unnecessary until any intervention is planned needs to be the prime point of focus especially when dealing with contagious diseases, especially self-limiting ones(9). New cases can be screened by the above mentioned method which unlike the present system keeps adding to the already present data, a continuous learning process(40) which is analyzed by ML systems thus making better diagnosis by pattern recognition as time goes by. The initial assessment if relevant enough could be used to make decisions on admissions/ stepping up or stepping down care, in accordance to the prognosis of individual cases. Identification and tracking the progress of high risk patients can be done remotely by AI systems with the help of connected devices and active patient participation(41). Mildly symptomatic patients can be monitored on a daily basis by AI systems once they have been diagnosed either clinically or by serological testing allowing the ML system to understand the patterns from data from millions of patients and thereby taking an informed decision with active patient involvement on the interventions needed. Follow up of patients along with vigilance for complications can be done with the help of these systems with a level of thoroughness which is not available with the current interactive systems.

ML learning for all its advantages does have a learning curve which depends on the input provided by the data, hence the importance of validated and accurate datasets(42). The issue of opacity has always been the ethical problem which can be overcome by self-supervised and reinforced learning system(43). Looking for rationalization and justification from an effective system would be the last thing in the mind of the authorities given the experiences we are having during this pandemic, and letting such debates take a toll on mortality on both patients and HCWs needs to be balanced with the benefits of the systems The biggest and most imminent limitation is the inability to use ML systems during the current epidemic due to a lack of big data on the same(44). Making this problem an opportunity to collect as much data as possible and then analyze them to validate the clinical findings would make the world ready for the next epidemic(45). Systems need to be put in place for data collection; analysis and constant improvements of the AI systems and algorithms need to be established as a proactive systemic process. The understanding of collecting veracious data and making an AI system which would use various processes like self-supervised learning, deep neural networks, inductive logic programming, explanation-based learning, utilizing difficult algorithms like natural language processing and decision trees(46) needs a proper moral and ethical framework which seems to be the most important need for the integration of ML systems into the present healthcare system. If properly planned and executed this model can indeed work as a lean model which is very effective and accurate given its limitations, especially in cases of epidemics and disasters. All biases including machine bias(47) and security of the whole system from cyber threats need to be considered as limitations of $\mathrm{AI}$ in general.

\section{TRANSLATION OF ML LEARNING FROM OTHER FIELDS TO CONTROL OF EPIDEMICS:}

ML learning has been the focal point of much debate as the future of healthcare lies in a delicate balance with constant reminders on the need for upgrade through unfortunate 
disasters as the COVID pandemic. The use of virtual assistants or chat bots has been used in answering questions, understanding the severity of diseases like asthma and $\operatorname{COPD}(48)$ through patient interaction along with the ability to call emergency services on behalf of patients citing exact details and location. Virtual assistants can interpret the syntax, semantics, and tone of the conversation to check for signs of mental or emotional health concerns(49). There are AI systems in place which have been able to use NLP to understand the chances of suicides through ML in cases of depression, which is a very positive development $(50)$. We are looking at a future where NLP would recognize personal pattern changes in voice in early detection of hoarseness of voice associated with occult carcinomas of the head, neck and thorax. Connected devices can provide support for caregivers and healthcare professionals to keep people out of hospitals, keep track of the comorbidities and reduce their visits to the doctor(46) especially in cases of epidemics. The combination of connected devices, apps, and virtual assistants make the home smarter and more conducive to screening and follow up of patients, ensuring the healthcare providers are constantly updated with patient conditions while empowering the patient(51). People with long-term conditions and the aging typically need increased diagnostic tests. Instead of turning up to a clinic or hospital to have urine and blood tests conducted, smart sensors in portable devices allow the test to be conducted in the comfort of the user's home(52). Results can then be wirelessly shared to their healthcare team as tests for cholesterol, cardiac function, HbA1c, fasting blood glucose, vitamin D levels, and insulin improve the convenience of performing repeated diagnostic tests, enabling quicker treatment, reducing the risk of complications, and hence reduction in avoidable healthcare spending. The translation of the same in the screening and follow up of patients during a pandemic can only result in effective curbing of the disease. As the database and evidence base expands, so too do the application of connected or wearable devices in detecting signs of disease(52). Digital therapeutics, or digital health, is an enhanced form of telemedicine that brings together digital and genomic technologies with health, lifestyle, and human factors to deliver personalized medicine to patients, enhancing the efficiency of healthcare delivery(53). Consultations through Skype or other video-conferencing facilities, EHRs remote monitoring, digital health education, and transmission of scans or images through telemedicine platforms, are all considered part of telemedicine(54). As the cost for virtual and merged reality devices becomes more affordable, virtual appointments will become commonplace, rather than a necessity as witnessed during the COVID pandemic(55). Virtual appointments will remove the inconvenience of attending a clinic, saving time, environmental resources and focusing healthcare professional time to where required, which when combined with the thoroughness of ML systems would be the best shot we have in cases of future epidemics. Virtual appointments will become as familiar as webinars, enabling stakeholders to be present without traveling and the present pandemic has already provided us with glimpses of what actually can be done and maybe this is where the future of efficient, lean and more convenient healthcare system lies(46).

\section{CONCLUSION}

AI systems and machine learning algorithms are indeed the future of efficient, lean and proactive healthcare systems. The current COVID pandemic has provided invaluable lessons on how this precious resource can be used and perhaps has provided a jumpstart to exploring various applications of AI in medicine. Use of ML systems seems to be the next logical step, at least in cases of epidemics and infectious diseases where the screening, diagnosis and follow up of patients without wasting and risking precious resources and protecting HCWs seems to be the path ahead in improving quality of care, clinical outcomes and patient engagement.

\section{ACKNOWLEDGEMENT}

This is an earnest attempt to acknowledge the time, effort and sacrifices of all the point of contact workers, the institutional authorities and the governments who have worked tirelessly to make the world a safer world to dwell in. The gratitude and respect to all the HCWs who have risked everything for the sake of others cannot be expressed in words and hence the need for everyone to contribute in accordance to their skill set to fight this pandemic as a unified species needs to acknowledge by one and all.

\section{REFERENCES}

[1] Anderson RM, Heesterbeek H, Klinkenberg D, Hollingsworth TD. How will country-based mitigation measures influence the course of the COVID-19 epidemic? The Lancet [Internet]. 2020 Mar [cited 2020 Apr 21];395(10228):931-4. Available from: https://linkinghub.elsevier.com/retrieve/pii/S0140673620 305675

[2] Madhav N, Oppenheim B, Gallivan M, Mulembakani P, Rubin E, Wolfe N. Pandemics: Risks, Impacts, and Mitigation. In: Jamison DT, Gelband H, Horton S, Jha P, Laxminarayan R, Mock CN, et al., editors. Disease Control Priorities: Improving Health and Reducing Poverty [Internet]. 3rd ed. Washington (DC): The International Bank for Reconstruction and Development / The World Bank; 2017 [cited 2020 Apr 21]. Available from: http://www.ncbi.nlm.nih.gov/books/NBK525302/

[3] McCall B. COVID-19 and artificial intelligence: protecting health-care workers and curbing the spread. Lancet Digit Health [Internet]. 2020 Apr [cited 2020 Apr 21];2(4):e166-7. Available from: https://linkinghub.elsevier.com/retrieve/pii/S2589750020 300546

[4] Munro $\alpha$ R, Gunasekara $\beta$ L, Nevins $\beta$ S, Polepeddi $\beta$ L, Rosen $\alpha$ E. Tracking Epidemics with Natural Language Processing and Crowdsourcing. 2012;

[5] Bedford J, Enria D, Giesecke J, Heymann DL, Ihekweazu C, Kobinger G, et al. COVID-19: towards controlling of a pandemic. The Lancet [Internet]. 2020 Mar [cited 2020 Apr 21];395(10229):1015-8. Available from:

https://linkinghub.elsevier.com/retrieve/pii/S0140673620 306735

[6] Prem K, Liu Y, Russell TW, Kucharski AJ, Eggo RM, Davies N, et al. The effect of control strategies to reduce social mixing on outcomes of the COVID-19 epidemic in Wuhan, China: a modelling study. Lancet Public Health [Internet]. 2020 Mar [cited 2020 Apr 21];S2468266720300736. Available from: https://linkinghub.elsevier.com/retrieve/pii/S2468266720 300736

[7] Wilder-Smith A, Freedman DO. Isolation, quarantine, social distancing and community containment: pivotal role for old-style public health measures in the novel coronavirus (2019-nCoV) outbreak. J Travel Med [Internet]. 2020 Mar 13 [cited 2020 Apr 
21];27(2):taaa020.

Available

from: https://academic.oup.com/jtm/article/doi/10.1093/jtm/taa a020/5735321

[8] Daniels N. Resource allocation and priority setting. In: Public health ethics: cases spanning the globe. Springer, Cham; 2016. p. 61-94.

[9] Adams JG, Walls RM. Supporting the Health Care Workforce During the COVID-19 Global Epidemic. JAMA [Internet]. 2020 Apr 21 [cited 2020 Apr 21];323(15):1439-40. Available from: https://doi.org/10.1001/jama.2020.3972

[10] Wang CJ, Ng CY, Brook RH. Response to COVID-19 in Taiwan: Big Data Analytics, New Technology, and Proactive Testing. JAMA [Internet]. 2020 Apr 14 [cited 2020 Apr 21];323(14):1341-2. Available from: https://doi.org/10.1001/jama.2020.3151

[11] Hadaya J, Schumm M, Livingston EH. Testing Individuals for Coronavirus Disease 2019 (COVID-19). JAMA [Internet]. 2020 Apr 1 [cited 2020 Apr 21]; Available from: https://jamanetwork.com/journals/jama/fullarticle/27642 38

[12] Parmet WE, Sinha MS. Covid-19 - The Law and Limits of Quarantine. N Engl J Med [Internet]. 2020 Apr 9 [cited 2020 Apr 21];382(15):e28. Available from: http://www.nejm.org/doi/10.1056/NEJMp2004211

[13] Wu Y-C, Chen C-S, Chan Y-J. The outbreak of COVID19: An overview. J Chin Med Assoc [Internet]. 2020 Mar [cited 2020 Apr 21];83(3):217-20. Available from: http://journals.lww.com/10.1097/JCMA.0000000000000 270

[14] COVID-19 National Emergency Response Center, Epidemiology \& Case Management Team, Korea Centers for Disease Control \& Prevention. Contact Transmission of COVID-19 in South Korea: Novel Investigation Techniques for Tracing Contacts. Osong Public Health Res Perspect [Internet]. 2020 Feb 28 [cited 2020 Apr 21];11(1):60-3. Available from: http://ophrp.org/journal/view.php?doi=10.24171/j.phrp.2 020.11.1.09

[15] Shi Y, Yu X, Zhao H, Wang H, Zhao R, Sheng J. Host susceptibility to severe COVID-19 and establishment of a host risk score: findings of 487 cases outside Wuhan. Crit Care [Internet]. 2020 Dec [cited 2020 Apr 21];24(1):108. Available from: https://ccforum.biomedcentral.com/articles/10.1186/s130 54-020-2833-7

[16] Khafaie MA, Rahim F. Cross-Country Comparison of Case Fatality Rates of COVID-19/SARS-COV-2. Osong Public Health Res Perspect [Internet]. 2020 Apr 30 [cited 2020 Apr 21];11(2):74-80. Available from: http://ophrp.org/journal/view.php?doi=10.24171/j.phrp.2 020.11 .2 .03

[17] Du R-H, Liang L-R, Yang C-Q, Wang W, Cao T-Z, Li $M$, et al. Predictors of Mortality for Patients with COVID-19 Pneumonia Caused by SARS-CoV-2: A Prospective Cohort Study. Eur Respir J [Internet]. 2020 Apr 8 [cited 2020 Apr 21];2000524. Available from: http://erj.ersjournals.com/lookup/doi/10.1183/13993003. 00524-2020
[18] Bao L, Deng W, Gao H, Xiao C, Liu J, Xue J, et al. Reinfection could not occur in SARS-CoV-2 infected rhesus macaques [Internet]. Microbiology; 2020 Mar [cited 2020 Apr 21]. Available from: http://biorxiv.org/lookup/doi/10.1101/2020.03.13.990226

[19] Lin Q, Zhu L, Ni Z, Meng H, You L. Duration of serum neutralizing antibodies for SARS-CoV-2: Lessons from SARS-CoV infection. J Microbiol Immunol Infect [Internet]. 2020 Mar [cited 2020 Apr 21];S168411822030075X. Available from: https://linkinghub.elsevier.com/retrieve/pii/S1684118220 $30075 \mathrm{X}$

[20] Syal K. COVID-19: Herd Immunity and Convalescent Plasma Transfer Therapy. J Med Virol [Internet]. 2020 Apr 13 [cited 2020 Apr 21]; Available from: http://doi.wiley.com/10.1002/jmv.25870

[21] The Lancet. COVID-19: protecting health-care workers. The Lancet [Internet]. 2020 Mar [cited $2020 \mathrm{Apr}$ 21];395(10228):922. Available from: https://linkinghub.elsevier.com/retrieve/pii/S0140673620 306449

[22] Grubaugh ND, Ladner JT, Lemey P, Pybus OG, Rambaut A, Holmes EC, et al. Tracking virus outbreaks in the twenty-first century. Nat Microbiol [Internet]. 2019 Jan [cited 2020 Apr 21];4(1):10-9. Available from: http://www.nature.com/articles/s41564-018-0296-2

[23] Delamater PL, Street EJ, Leslie TF, Yang YT, Jacobsen KH. Complexity of the Basic Reproduction Number (R 0 ). Emerg Infect Dis [Internet]. 2019 Jan [cited 2020 May 24];25(1):1-4. Available from: http://wwwnc.cdc.gov/eid/article/25/1/171901_article.htm

[24] Randolph HE, Barreiro LB. Herd Immunity: Understanding COVID-19. Immunity [Internet]. 2020 May [cited 2020 May 24];52(5):737-41. Available from: https://linkinghub.elsevier.com/retrieve/pii/S1074761320 301709

[25] Viceconte G, Petrosillo N. COVID-19 R0: Magic number or conundrum? Infect Dis Rep [Internet]. 2020 Feb 24 [cited 2020 Apr 21];12(1). Available from: https://www.pagepress.org/journals/index.php/idr/article/ view/8516

[26] Sanche S, Lin YT, Xu C, Romero-Severson E, Hengartner N, Ke R. The Novel Coronavirus, 2019$\mathrm{nCoV}$, is Highly Contagious and More Infectious Than Initially Estimated [Internet]. Epidemiology; $2020 \mathrm{Feb}$ [cited 2020 May 24]. Available from: http://medrxiv.org/lookup/doi/10.1101/2020.02.07.20021 154

[27] Elsevier. How to survive a plague - why AI is key to fighting the next major pandemic [Internet]. Elsevier Connect. [cited 2020 Apr 21]. Available from: https://www.elsevier.com/connect/how-to-survive-aplague-why-ai-is-key-to-fighting-the-next-majorpandemic

[28] Wittbold KA, Carroll C, Iansiti M, Zhang HM, Landman AB. How Hospitals Are Using AI to Battle Covid-19 [Internet]. Harvard Business Review. 2020 [cited 2020 Apr 22]. Available from: https://hbr.org/2020/04/howhospitals-are-using-ai-to-battle-covid-19 
[29] Lysaght T, Lim HY, Xafis V, Ngiam KY. AI-Assisted Decision-making in Healthcare: The Application of an Ethics Framework for Big Data in Health and Research. Asian Bioeth Rev [Internet]. 2019 Sep [cited 2020 Apr 22];11(3):299-314. Available from: http://link.springer.com/10.1007/s41649-019-00096-0

[30] Hollander JE, Carr BG. Virtually Perfect? Telemedicine for Covid-19. N Engl J Med [Internet]. 2020 Apr 30 [cited 2020 May 16];382(18):1679-81. Available from: http://www.nejm.org/doi/10.1056/NEJMp2003539

[31] Forte JC, van der Horst ICC. Comorbidities and medical history essential for mortality prediction in critically ill patients. Lancet Digit Health [Internet]. 2019 Jun [cited 2020 Apr 22];1(2):e48-9. Available from: https://linkinghub.elsevier.com/retrieve/pii/S2589750019 300305

[32] Meskó B, Hetényi G, Győrffy Z. Will artificial intelligence solve the human resource crisis in healthcare? BMC Health Serv Res [Internet]. 2018 Dec [cited 2020 Apr 22];18(1):545. Available from: https://bmchealthservres.biomedcentral.com/articles/10.1 186/s12913-018-3359-4

[33] Chouvarda IG, Goulis DG, Lambrinoudaki I, Maglaveras N. Connected health and integrated care: Toward new models for chronic disease management. Maturitas [Internet]. 2015 Sep [cited 2020 Apr 22];82(1):22-7. Available from: https://linkinghub.elsevier.com/retrieve/pii/S0378512215 006052

[34] Benke K, Benke G. Artificial Intelligence and Big Data in Public Health. Int $\mathbf{J}$ Environ Res Public Health [Internet]. 2018 Dec 10 [cited 2020 Apr 22];15(12):2796. Available from: http://www.mdpi.com/1660$4601 / 15 / 12 / 2796$

[35] Macaulay T. Researchers want your voice to train coronavirus-detecting AI [Internet]. The Next Web. 2020 [cited 2020 Apr 22]. Available from: https://thenextweb.com/artificialintelligence/2020/04/07/researchers-want-your-voice-totrain-coronavirus-detecting-ai/

[36] Shi Y, Liu H, Wang Y, Cai M, Xu W. Theory and Application of Audio-Based Assessment of Cough. J Sens [Internet]. 2018 [cited 2020 Apr 22];2018:1-10. Available from: https://www.hindawi.com/journals/js/2018/9845321/

[37] Project Coswara: \#COVID19 Diagnostic Tool by Indian Institute of Science: Submit Your Voice Samples! [Internet]. NoticeBard. 2020 [cited 2020 Apr 22]. Available from: https://www.noticebard.com/coswaravoice-samples-collection/

[38] Amisha, Malik P, Pathania M, Rathaur V. Overview of artificial intelligence in medicine. J Fam Med Prim Care [Internet]. 2019 [cited 2020 Apr 15];8(7):2328. Available from:

http://www.jfmpc.com/text.asp?2019/8/7/2328/263820

[39] Kelly CJ, Karthikesalingam A, Suleyman M, Corrado G, King D. Key challenges for delivering clinical impact with artificial intelligence. BMC Med [Internet]. 2019 Dec [cited 2020 Apr 22];17(1):195. Available from: https://bmcmedicine.biomedcentral.com/articles/10.1186 /s12916-019-1426-2
[40] Liu B. Lifelong machine learning: a paradigm for continuous learning. Front Comput Sci [Internet]. 2017 Jun [cited 2020 Apr 22];11(3):359-61. Available from: http://link.springer.com/10.1007/s11704-016-6903-6

[41] Ahmed Z, Mohamed K, Zeeshan S, Dong X. Artificial intelligence with multi-functional machine learning platform development for better healthcare and precision medicine. Database [Internet]. 2020 Jan 1 [cited 2020 Apr 22];2020:baaa010. Available from: https://academic.oup.com/database/article/doi/10.1093/d atabase/baaa010/5809229

[42] Webb GI, Sammut C, Perlich C, Horváth T, Wrobel S, Korb KB, et al. Learning Curves in Machine Learning. In: Sammut C, Webb GI, editors. Encyclopedia of Machine Learning [Internet]. Boston, MA: Springer US; 2011 [cited 2020 Apr 22]. p. 577-80. Available from: http://link.springer.com/10.1007/978-0-387-30164$8 \_452$

[43] Jing L, Tian Y. Self-supervised Visual Feature Learning with Deep Neural Networks: A Survey. ArXiv190206162 Cs [Internet]. 2019 Feb 16 [cited 2020 Apr 9]; Available from: http://arxiv.org/abs/1902.06162

[44] AI runs smack up against a big data problem in COVID19 diagnosis | ZDNet [Internet]. [cited 2020 Apr 22]. Available from: https://www.zdnet.com/article/ai-runssmack-up-against-a-big-data-problem-in-covid-19diagnosis/

[45] Big data versus COVID-19: opportunities and privacy challenges | Bruegel [Internet]. [cited 2020 Apr 22]. Available from: https://www.bruegel.org/2020/03/bigdata-versus-covid-19-opportunities-and-privacychallenges/

[46] Panesar A. Machine Learning and AI for Healthcare: Big Data for Improved Health Outcomes. Berkeley, CA: Apress Imprint,Apress; 2019.

[47] Parikh RB, Teeple S, Navathe AS. Addressing Bias in Artificial Intelligence in Health Care. JAMA [Internet]. 2019 Dec 24 [cited 2020 Apr 22];322(24):2377. Available from: https://jamanetwork.com/journals/jama/fullarticle/27561 96

[48] Esteban C, Moraza J, Esteban C, Sancho F, Aburto M, Aramburu A, et al. Machine learning for COPD exacerbation prediction. In: 12 Rehabilitation and Chronic Care [Internet]. European Respiratory Society; 2015 [cited 2020 Apr 22]. p. OA3282. Available from: http://erj.ersjournals.com/lookup/doi/10.1183/13993003. congress-2015.OA3282

[49] Medeiros J. Virtual Assistants Can Detect Your Bad Mood And Do Something About It [Internet]. [cited 2020 Apr 22]. Available from https://www.voicesummit.ai/blog/virtual-assistants-candetect-your-bad-mood-and-do-something-about-it

[50] AI Helps Identify People at Risk for Suicide - WSJ [Internet]. [cited 2020 Apr 22]. Available from: https://www.wsj.com/articles/ai-helps-identify-people-atrisk-for-suicide-1519400853

[51] Virtual health care: Health consumer and physicians reaction | Deloitte Insights [Internet]. [cited $2020 \mathrm{Apr}$ 22]. Available from: https://www2.deloitte.com/us/en/insights/industry/health- 
care/virtual-health-care-health-consumer-and-physiciansurveys.html

[52] Dias D, Paulo Silva Cunha J. Wearable Health Devices-Vital Sign Monitoring, Systems and Technologies. Sensors [Internet]. 2018 Jul 25 [cited 2020 Apr 22];18(8):2414. Available from: http://www.mdpi.com/1424-8220/18/8/2414

[53] Nordyke RJ, Appelbaum K, Berman MA. Estimating the Impact of Novel Digital Therapeutics in Type 2 Diabetes and Hypertension: Health Economic Analysis. J Med Internet Res [Internet]. 2019 Oct 9 [cited 2020 Apr 22];21(10):e15814. Available from: https://www.jmir.org/2019/10/e15814

[54] Breen G-M, Matusitz J. An Evolutionary Examination of Telemedicine: A Health and Computer-Mediated Communication Perspective. Soc Work Public Health [Internet]. 2010 Jan [cited 2020 Apr 22];25(1):59-71. Availablefrom:https://www.tandfonline.com/doi/full/10. 1080/19371910902911206

[55] Practice Guidance for COVID-19 [Internet]. [cited 2020 Apr 22]. Available from: https://www.psychiatry.org/psychiatrists/covid-19coronavirus/practice-guidance-for-covid-19 